\title{
The Role of Architectural Considerations in Seismic Performance of Buildings: A Case Study in Iran
}

\author{
Babak Omidvar, Alireza Sadeghian and Mehdi Nojavan \\ Graduate Faculty of Environment, University of Tehran, Tehran 11369, Iran
}

\begin{abstract}
Experience from recent earthquakes such as Gilan, Zanjan, Bam and Lorestan earthquakes in Iran indicated that the constructed buildings are vulnerable against earthquake. Vulnerability of these structures is due to various reasons such as designing without considering seismic regulations, problems of regulations (design goals), implementation problems, changing of the building occupancy class, increasing the weight of building stories, adding new stories to the building and changing in architecture of building without considering structural system. So the main objective of this research is to examine the features of building configuration and their effects as for the damages to buildings in past earthquakes. For this purpose, initially four occurred earthquakes in Iran are selected as case study. Then three types of buildings (steel structure, concrete structure and masonry buildings) are analyzed with details. Results showed that the most of damages are occurred in the old steel structures and masonry buildings which their ages are more than 25 years. The study showed that most of the buildings in the study area are steel structure and masonry buildings while concrete structures are infrequent which most of them had no or slight damages. Therefore, the importance and need to enhance the performance of available buildings against earthquake forces by rehabilitating methods would be more important than before. Also results indicated that the decisions related to architectural plan which have significant effect on seismic performance of buildings, can be divided into three categories: configuration of building, restrictive formal architectural plan and dangerous structural components, as these categories are not obstacle of each other, it is possible that each category has an influential effect on others. So organizing the design decisions in this way is very important so as to manage their effects and interdependencies.
\end{abstract}

Key words: Structural plan, architectural plan, seismic performance, building configuration.

\section{Introduction}

Buildings built over the last years in Iran, are considered the most serious problems in risk and vulnerability assessment of cities and villages. Given the recent earthquakes in areas such as Bam and Lorestan and status of building, there is a risk of injury in many existing buildings. Given that it is impossible to prevent earthquakes, it is necessary to minimize damages by retrofitting of existing vulnerable structure. The earthquake resistance of buildings depends upon three quite different processes in design [1]. There is the overall layout of the building which determines the magnitude of the forces which come onto the building and their distribution.

Corresponding author: Mehdi Nojavan, Ph.D., research fields: natural disasters planning and management, loss estimation and risk assessment. E-mail: nojavan_mehdi@ut.ac.ir.
Secondly, there is the ability of the various parts of the building to resist these forces. Thirdly, there are those aspects of construction, which are rarely mentioned at all, non-structural or architectural aspects of building, non-load bearing walls and finishes [1]. Although the criteria to provide resistance against earthquake are met through structures, the related architectural plan will play an important role in determining the earthquake performance of buildings. Damage to the architectural elements, during an earthquake could cause major economic losses even with minor structural damage [2]. So, the architect should produce the seismic design of structure as effective as possible. The structure should meet the functional and aesthetic goals of the building as well. Architectural plan decisions which affect the seismic performance of building are divided into three categories, building configuration, restrictive 
architectural plan of seismic issues, dangerous structural components.

The term build configuration refers to the size, form and three-dimensional shape of the building. It also includes the location, approximate size and shape of structural components because these cases are normally characterized by the concept of architecture. Also, the concept of building or its conceptual scheme, are used inaccurately to determine the configuration. To be precise, building configuration only refers to its geometrical characteristics. Restrictive architectural plan of seismic issues also refers to the details of architectural plan such as columns or walls which could affect structural details in a way that does not allow for a good seismic design. Dangerous structural components means that if these components are designed inappropriately against seismic forces, they may themselves endanger the life. Additionally, they may be among the main reasons of loss of property and injury to necessary facilities and other services may result in buildings not functioning properly. For our purposes, we could define building configuration as size and shape: The shape of building is composed of nature, size and status of structural components. We need such a generalized definition of building configuration because there is a complicated relationship among the seismic function of all these components.

The nature, size and status of non-structural components which could affect the structural function of building or components which are important themselves, could be a part of initial concept of building or to be added to later on.

The purpose of this article is to examine the features of building configuration and their effects as for the damages to buildings in past earthquakes.

\section{General Effect of Building Configuration}

One of the most important factors that determines the extent of damage during an earthquake is the shape and configuration of the building [3]. Building configuration plays an important role in determining distribution of seismic forces over the building and also affects the relative size of these forces. For a given ground motion, the important determinant of the size of inertial forces is building's mass. The size and shape of the building (along with materials chosen) determine the mass, and the plan determines area and volume. By plan, we mean a list of spaces, activities and facilities needed for the building. However, for any given plan, different configurations may render a solution and they are the variables of these configurations which affect the distribution of inertia forces caused by earthquakes. Therefore, the discussion of the impact of configuration on seismic performance, leads to the identification of those variables that affect the distribution of inertia forces. These variables indicate irregularities or deviation from regular configuration, which in clash with lateral forces, are optimal or ideal. An ideal seismic design which in terms of architecture provides a utile configuration should have the following features: low ratio of height to width, moderate resistance, homogenous view and cross-section, maximum torsional strength (due to the location of shear walls and bracings), short spans, direct load path and same height floors.

The question is why these models cannot be used in all buildings and why it is necessary to make changes in configurations that may be detrimental to seismic performance of buildings. The answer to this question lies in combining functional requirements and creativity. There are times that functional requirements imposed a certain configuration which is less than ideal in terms of seismic activity. Our taste and our need to diversity in environmental construction, make a so different place of a city made up only of ideal configurations. But in case of irregular buildings, there is no quantitative basis for determining the relative importance of a certain irregularity.

A good review of past earthquakes shows that 
irregularities are often related to configuration. Therefore, issues of architectural considerations can be classified into the four following categories: plan configuration issues, vertical configuration issues, structures limiting architectural details and problem of adjacent floors.

\section{Problems of Plan Configuration}

\subsection{Depressed Corners}

Depressed corner is a common feature of all building configurations and can be seen in the plan in forms of $\mathrm{L}, \mathrm{T}, \mathrm{H},+$ or a combination of them. There are two related problems that are caused by these forms. The first problem is that these kinds of buildings change the stiffness, hence, the relative motions between different parts of the building lead to local stress concentration in depressed corner (Fig. 1) $[3,4]$. The second problem is about torsion. The problem arises because in this figure, center of mass and center of rigidity do not match geometrically for all possible earthquake directions (Fig. 2).

To deal with this problem, there are two basic solutions. Separating the building structurally in simple ways, and fastening buildings firmly to each other in the area of stress concentration lines and using durable components to reduce torsion.

\subsection{Perimeter Stiffness Changes}

Increased rigidity in building's perimeter increases the resistance against earthquake-caused torsion. If different changes are seen in perimeter stiffness, then the center of mass and center of stiffness would not match and torsional forces cause the building rotates around its stiffness center. This problem could be seen even in buildings with simple and symmetric appearance (Fig. 3). The weaknesses of open-front designs have been discussed by Degenkolb in 1977 [5].

To deal with this problem, the chance of torsion should be reduced and the stiffness of building's perimeter should be uniformed. To this end, three methods are proposed. The first one is to use framed structures with nearly the same strength and stiffness for the entire perimeter of the building.

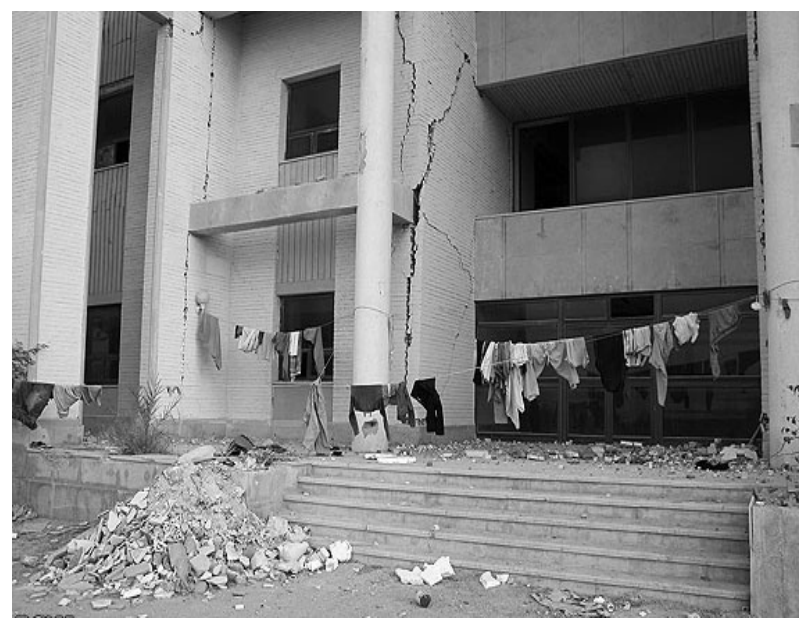

Fig. 1 Local stress concentration in the corner, Qeshm earthquake [6].
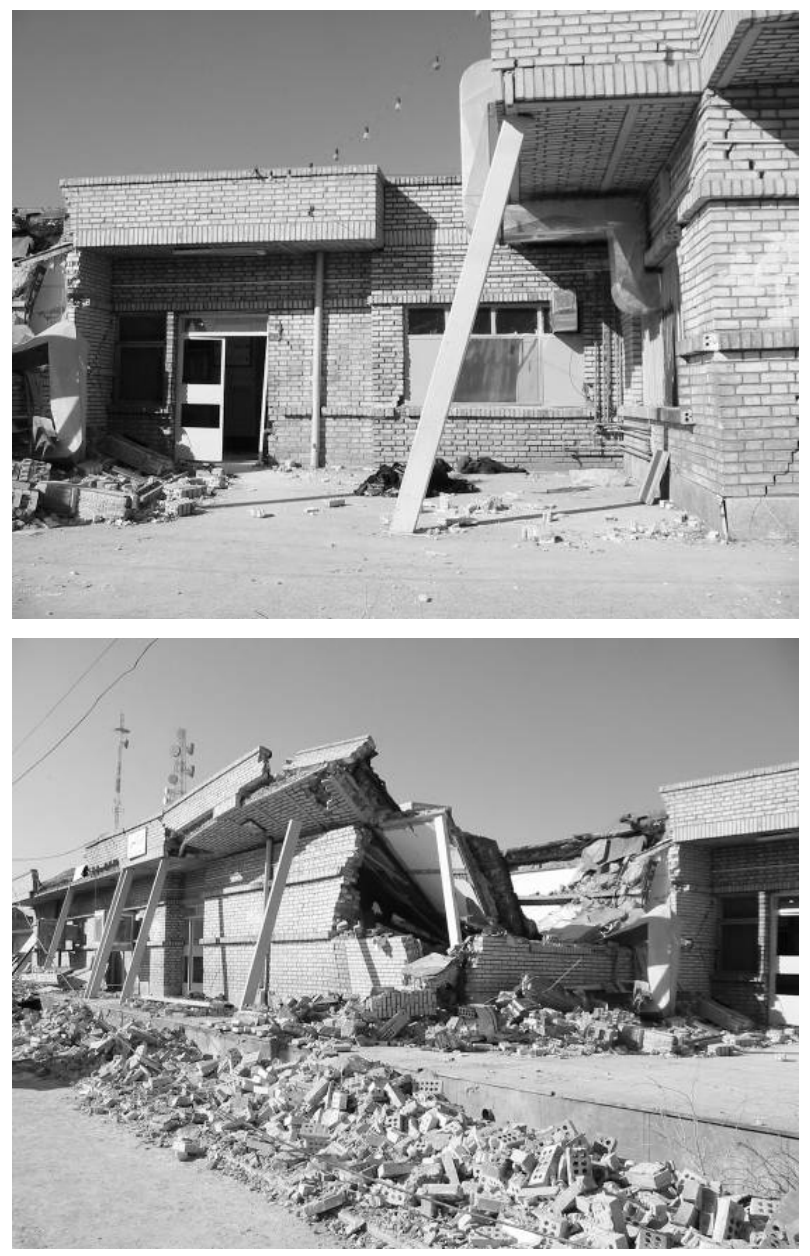

Fig. 2 Hospital building demolish because of depressed corner (photo by researcher). 

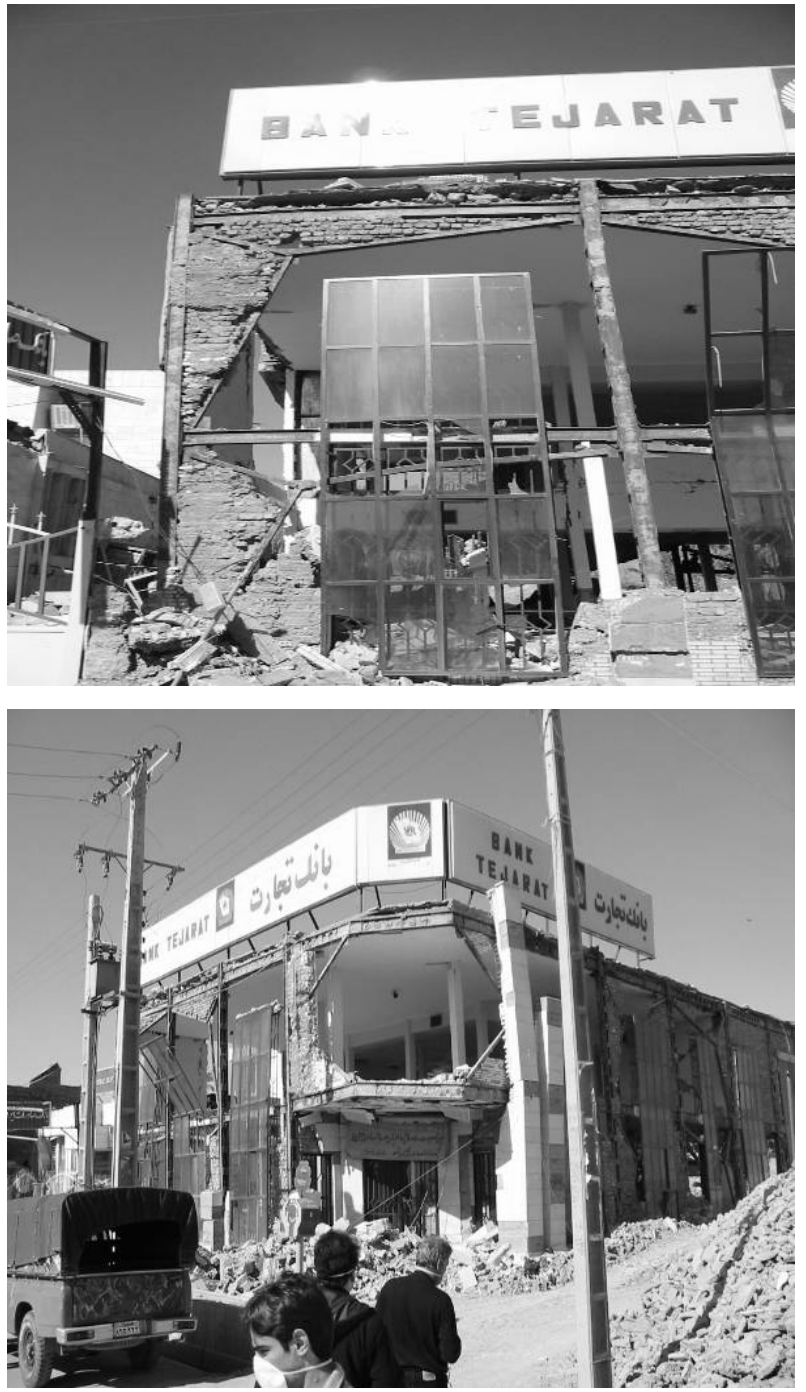

Fig. 3 Open space around the buildings, Bam earthquake (photo by researcher).

The second method is to increase the rigidity of open views through adding shear walls. The third solution is using braced frames in open front part which function as rigid walls. Certainly the feasibility of the last method depends on size of openings.

\subsection{Unparallel Systems}

If components of resistance to vertical load are unparallel with main orthogonal axes of the lateral load resisting system, or are not symmetric around them, there would be a non-parallel system which increase the probability of existence of torsion forces, because the center of mass and center of stiffness do not match (Fig. 4). Furthermore, the narrower parts of the building are more flexible than wider parts and this leads to torsion. A good example of this is a triangle or wedge-shaped building which is the result of street intersection at a steep angle. Therefore, to reduce the effect of torsion we need to pay special attention. Generally, opaque walls should be designed as frames covered with lightweight materials so that the difference of stiffness between this wall and other parts of the structure reduces. To increase the torsional strength of the narrower parts of building, certain design solutions could be rendered in other ways, though its realization is in conflict with preserving the desired open views or internal spaces.

\subsection{Diaphragm Configuration}

Diaphragm configuration refers to the shape and arrangement of horizontal resistant components which transmit forces between the vertical resistant parts [4]. Diaphragms function as a horizontal pole. The diaphragm is the pole itself and its edges are the pole's wings. Diaphragm's opening and geometrical irregularities similar to those seen in other components lead to torsion and concentration of stresses (Fig. 5).

Three methods are proposed to deal with this problem:

- Preventing the interference of openings with connection of diaphragms to walls or frames;

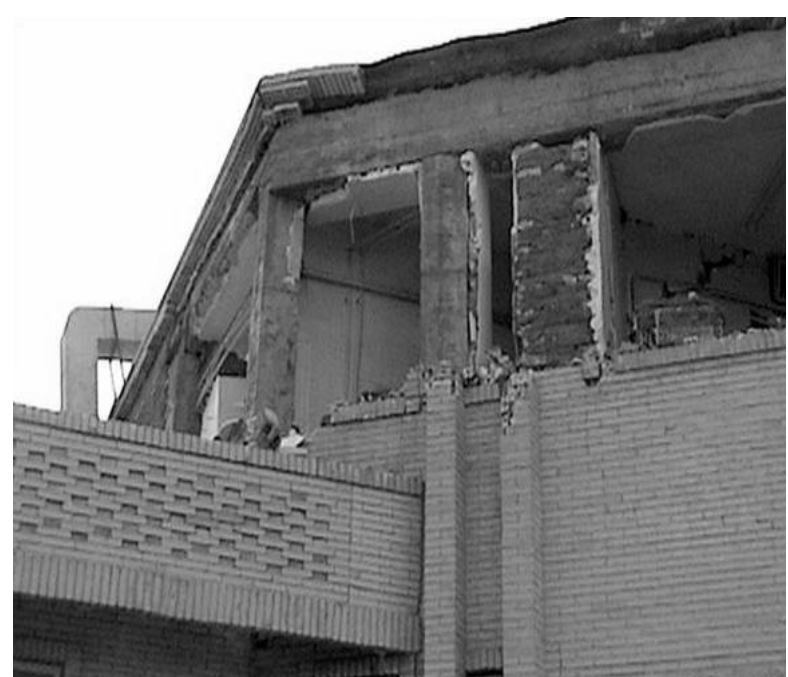

Fig. 4 Unparallel system, Bam earthquake [7]. 


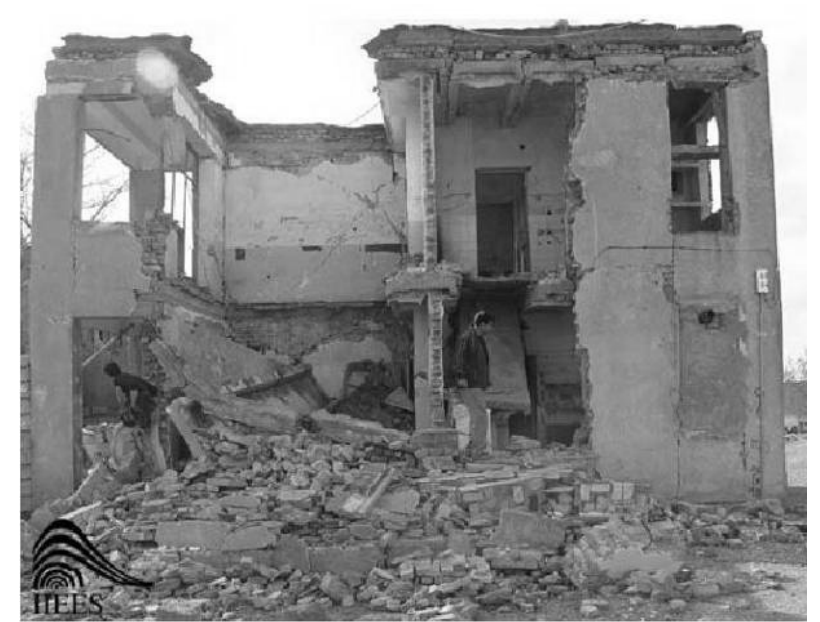

Fig. 5 Total destruction because of opening in diaphragm, Zarand Earthquake [8].

- Putting openings at suitable intervals to provide enough rigidity for diaphragm;

- Preventing the disconnection of collectors and diaphragms' tension members through openings.

\section{Problems of Vertical Configuration}

Problems that may arise in connection with vertical configuration could be categorized as follows.

\subsection{Soft and Weak Stories}

Soft and weak story is a story, far less stiff or resistant than the immediate stories above it [9]. When the first story is a soft one, the most critical situation will arise, because at this level loads are the heaviest. The main feature of the first soft story is discontinuities in stiffness which happens in the second story's connection (Fig. 6).

Generally, it could be said that problems associated with soft story result from four main situations:

- In structures that the first story is too higher than the upper stories, the first story will be less rigid and with more deflection;

- Sudden change of stiffness in the second story, even when all stories are of the same height;

- Using a discontinuous shear wall, where walls that do not extend to the foundation, bear shear forces but these walls are stopped at the level of the second floor and create a situation similar to the second situation;
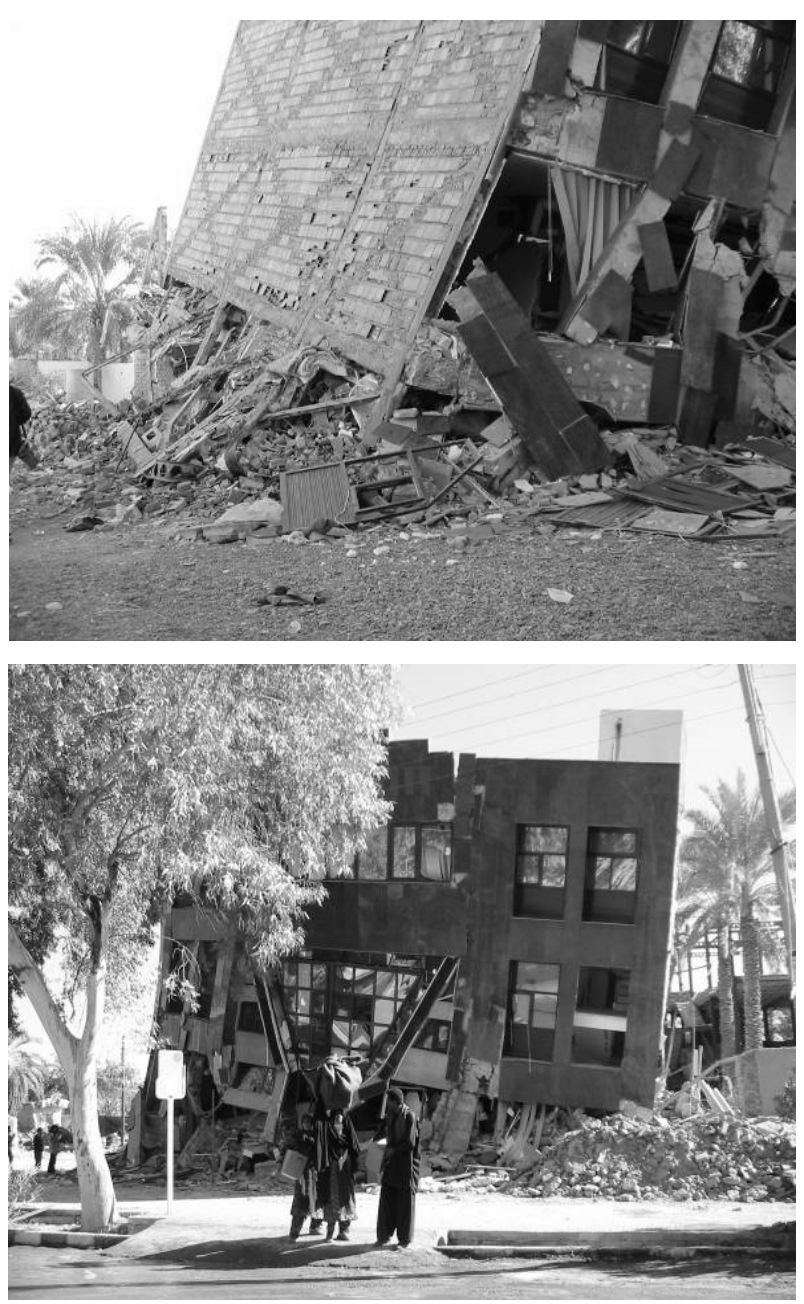

Fig. 6 Demolition of Kimia building because of the first soft story and short half-story column, Bam earthquake (photo by the researcher).

- Discontinuous load paths are created due to changes in the vertical and horizontal structure in the second story.

4.2 Columns, Changes in Stiffness, Strong Beams Weak Columns

Here the use of columns with different stiffness in one story is discussed. Seismic load is distributed in proportion to the stiffness of resistant components. Therefore, in case of any change in the stiffness of bearing columns (or walls), the more stiff columns (which are usually shorter), absorb more forces. The point is that rigidity (and therefore force) change almost according to the third power of the columns' length. Therefore, the short columns that support a 
story absorb the most force exerted to that story and as a result, there is a probability of rupture. It is usually possible that such an arrangement involves deep and rigid beams which result to a considerable weaker performance of columns (Fig. 7). Such a design is in conflict with basic principles of seismic design, which strives to design structures so that under severe earthquake forces, plastic hinge develop in beams sooner than columns. Combination of columns with different level of stiffness in different views may lead to torsion. The root of change in stiffness along the column is architectural consideration. Building on hillside, filling parts of the frames with non-structural but hard material to make long strips of windows, making some of the columns more rigid by constructing a half-story or attic while other parts remain with an uncontrolled full height are among the main issues.

The general solution, is matching seismic design details with architectural requirements. By ensuring that deep perimeter beams have been separated from columns, weak column-strong beam would be avoidable. This way, length of columns around a view could be roughly equal or we can use horizontal brace to equalize the stiffness of a set of columns that are variable in height. Heavy non-structural walls should be separated from columns to ensure that short-column situation will not be created.

\subsection{Vertical Set-Backs}

Vertical set-backs are horizontal deflection in the external wall of the structure. The main problem of this type of buildings is the sudden change in stiffness and strength such a complex configuration will likely cause a problem in recess axis (Fig. 8). This configuration can also be thought of as a vertical indented corner.

Although set-back usually occur in a single building, it may also occur as a result of connecting building with different heights that do not have enough seismic isolation. Generally, conceptual solutions for set-backs problems are similar to solutions for its horizontal opposite, i.e., indented corners in plan. To avoid any problem, there should be a complete separation in the plan so that, different
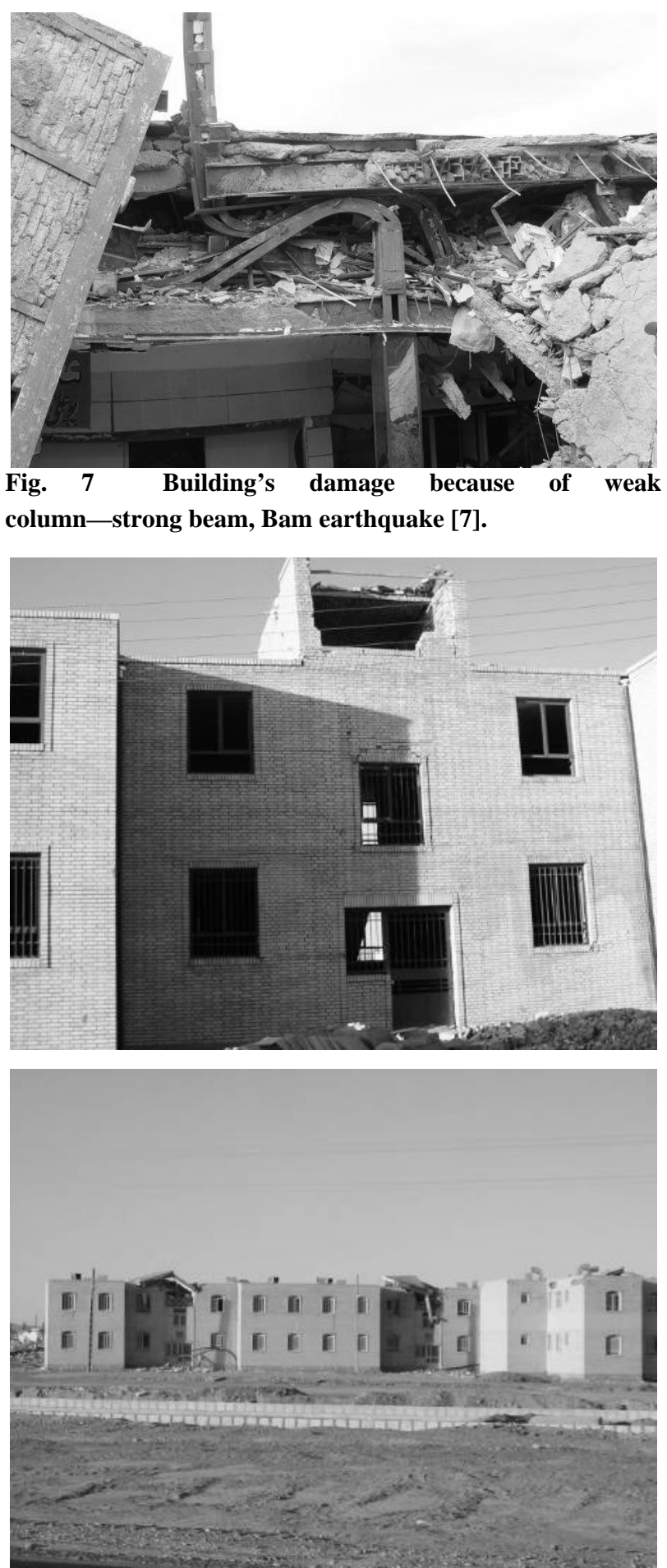

Fig. 8 Damage of building's mound, Bam earthquake (photo by the researcher). 
parts of the building react independently. Otherwise, the set-backs should be arranged in a way to match the size of typical openings.

\section{Structure's Limiting Architectural Details}

The term "structure's limiting architectural details" refers to the detailed design of detailed architecture of a component or connection which prevents the use of a good seismic design in designing the structure. This represents a very small sample of general issues related to building configuration. Architectural details may create dimensional or spatial constraints in structural design which lead to weakness or eccentricity of forces and this consequently results in tension concentration or local torsion. In beam-column connections which are under a heavy tension, but are considered an important element in building aesthetic design, the above mentioned problem becomes more critical. Structural details provide ideally direct load transfer and minimum local eccentricity. Architectural details may lead to inappropriate sizes and discontinuous or eccentric load path. This problem is particularly important in reinforced concrete structures in which architectural details may provide insufficient space for appropriate rebar establishment (Fig. 9). Detailed design is an important element in architecture. Design of environmental beam-column connection, for example, may induce horizontal, vertical or neutral focus in a building. However, it is possible that the architect could not understand the structural necessity of these changes. Another example is the use of cross-section incremental changes or creating indent in columns. Architects create indent mostly to emphasize on the line where materials are separated, particularly when materials are of different kinds or intersect each other at right angle. The architect and building engineer need to have close cooperation to insure that architectural details will not lead to development of inappropriate constraints in structure design.

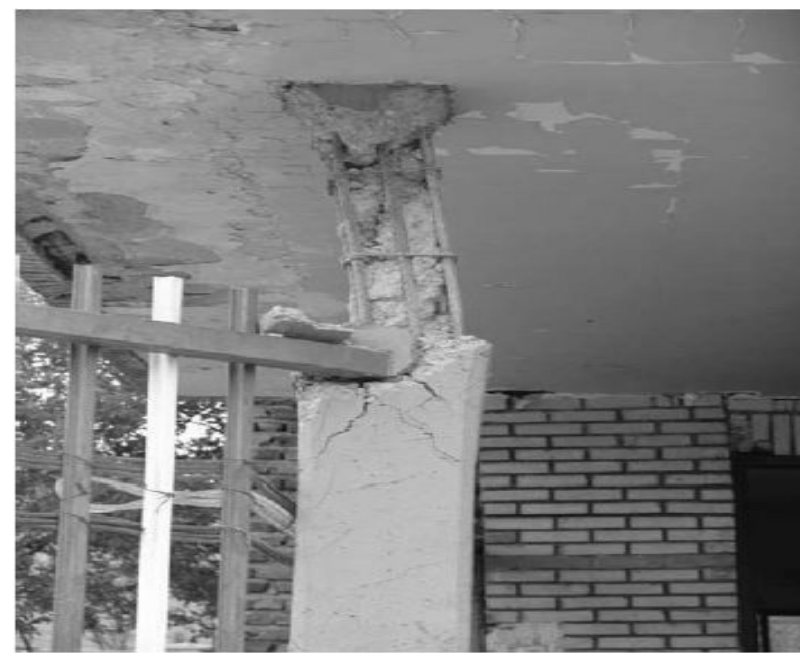

Fig. 9 Silakhor earthquake [10].

\section{Problems of Adjacency (Hitting)}

Pounding refers to the damage occurs as a result of collision between two buildings or different parts of a single building. The probability of hitting is a function of lateral displacement of adjacent buildings (or parts of a single building). Lateral displacement is calculated by applying forces to the building regulation plan. Because the estimated forces are less than the amount that actually occurs, the estimated lateral displacement should be corrected to obtain a more realistic estimation of building displacement. In other words, lateral displacement could be estimated more carefully by considering all the predicted factors. Pounding is usually discussed in configuration section, because it depends on the location of building's establishment compared to other structures and it is an initial decision of architecture. This leads to important architectural implications for building construction in dense urban areas because in worst-case scenarios, it will result in isolation of large buildings and thus significant loss of usable space. It is unrealistic to assume the lateral displacement according to regulations is precise but realistic estimations may provide very large numbers as for the worst case scenario. A solution to this problem is to determine the required distance as the total lateral displacements which are calculated for each building 
separately. This calculation is based on the fact that displacement growth in each floor is equal to the yield point of that same floor and arbitrarily the yield displacements of two lower floors are increased to two times [11]. Another solution, mentioned in old bylaws, is that seam discontinuity must be one inch plus one-second inch for 10 feet height in 20 feet height and above [5]. Another possible solution is placing energy-absorbing materials between buildings.

\section{Conclusions}

In this paper, the role of architectural considerations in seismic performance of buildings is studied. The results showed that seismic design is a shared responsibility between the architect and structural engineer which stems from the physical relationship between architectural forms and structural systems and though the regulations of providing seismic resistance will be realized through structure, the architectural plan and decisions which develop that, plays an important role in determining the performance of buildings against earthquakes. Relationship between architecture and engineering problems requires that the architect and structure engineer cooperate with each other from the beginning of a project. However, for reasons of economy, culture and taste, such cooperation does not happen often and we experience considerable problems in buildings' structural performance which may result in disasters which is observed clearly in the study area especially in the masonry buildings. The results also showed that architectural plan decisions, which affect seismic performance of buildings, are divided into three categories: (1) building configuration; (2) restrictive architectural plan of seismic issues; (3) dangerous structural components. None of them omit the other and each category may affect the two others. Therefore, decision making in this way is useful to clarify their effects and interaction.

\section{References}

[1] H. Arbabian, The role of architects in seismic design: What we can learn from traditional construction, in: International Conference on the Seismic Performance of Traditional Buildings in Istanbul, Turkey, 2007.

[2] J.L. Lagorio, Earthquakes: An Architect's Guide to Nonstructural Seismic Hazards, John Wiley \& Sons, New York, 1990.

[3] F.M. Saradj, Seismic issues in the design the process: The role of architect in seismic safety issues in design process, International Journal of Engineering Science 19 (6) (2008) 9-20.

[4] Lorant Group, Seismic Design Principles, http://www.wbdg.org/design/seismic_design.php/ (accessed Mar. 15, 2012).

[5] H. Degenkolb, Seismic Design: Structural Concepts, Summer Seismic Institute for Architectural Faculty, AIA Research Corp, Washington, 1977.

[6] ISNA (Iranian Students' News Agency), 2005, http://www.isna.ir/ (accessed Dec. 21, 2012).

[7] IIEES (International Institute of Earthquake Engineering and Seismology), Bam earthquake report, Tehran, Iran, 2003.

[8] IIEES (International Institute of Earthquake Engineering and Seismology), Preliminary report of Dahouiyeh (Zarand-Kerman) Earthquake Identification Group: Behavior and Performance of Buildings, Tehran, Iran, 2003.

[9] J. Ambrose, D. Vergun, Design for Earthquakes, John Wiley \& Sons, New York, 1999.

[10] IIEES (International Institute of Earthquake Engineering and Seismology), Darbe Astaneh Silakhor Earthquake, Earthquake identification report, Tehran, Iran, Mar. 31, 2006.

[11] J.A. Blume, N.M. Newmark, L.H. Corning, Design of Multistory Concrete Buildings for Earthquake Motions, Port-land Cement Assoc., Skokie, IL, 1961. 